УДК 677.074

\title{
ЗНАЧЕНИЕ ЛЬНЯНЫХ ТКАНЕЙ ДЛЯ ЛЕТНЕЙ ОДЕЖДЫ
}

Тихомиров Геннадий Александрович

Профессор

Буслаев Сергей Николаевич

Преподаватель

Институт пищевых технологий и дизайна - филиал Нижегородского государственного инженерно-экономического университета

Аннотация: В статье подчеркиваются положительные потребительские и отличительные свойства льняных тканей, определяющие их применение для изготовления летней одежды. На основании социологического исследования подтверждается повышение интереса потребителей к летней одежде из льняных тканей, а также показывается их отношение к льняным тканям разного сырьевого состава.

Ключевые слова: ассортимент, исследование, летняя одежда, льняные ткани, предпочтения, свойства.

\section{THE IMPORTANCE OF LINEN FABRICS FOR SUMMER CLOTHING}

\section{Tikhomirov Gennady Alexandrovich Buslaev Sergey Nikolaevich}

\footnotetext{
Abstract: The article emphasizes the positive consumer and distinctive properties of linen fabrics that determine their use for the manufacture of summer clothes. On the basis of a sociological study, the increase in consumer interest in summer clothes made of linen fabrics is confirmed, and their attitude to linen fabrics of different raw materials is shown.

Key words: assortment, research, summer clothes, linen fabrics, preferences, properties.

Под одеждой понимается совокупность предметов, покрывающих тело человека и несущих защитные функции от неблагоприятных воздействий
} 


\section{СИНТЕЗ МЕЖДИСЦИПЛИНАРНОГО НАУЧНОГО ЗНАНИЯ КАК ФАКТОР РАЗВИТИЯ СОВРЕМЕННОЙ НАУКИ}

окружающей среды. Одежда, которую носят летом, так и называется - летняя, а одна из ее функций - защита от жары и зноя [1].

Наиболее популярным мнением для выполнения этой функции является применение хлопчатобумажных тканей, имеющих хорошие гигиенические свойства.

Однако в последнее время возрос интерес к льняным тканям. Тенденции моды повлияли на рост потребности и, в свою очередь, привели к расширению ассортимента льняных тканей.

Назначение определяет ассортиментные группы льняных тканей. Это ткани костюмно-платьевого и блузочно-сорочечного ряда (которые подвержены самому частому обновлению), бельевые, мебельно-декоративные. Все они вырабатываются с самыми разнообразными видами отделки. В большей части их выпускают отбеленными, гладкокрашеными, пестроткаными, набивными, жаккардовыми, часто с умягчающей отделкой, что придает им некий оригинальный внешний вид. Это развенчивает бытовавшее когда-то мнение о том, что льняные ткани - это грубоватые полотна неприглядного серого цвета [2]. Умягчение осуществляется путем химической и механической обработки. Надо сказать, что при этом немного снижается прочность, но это мало влияет на потребительские свойства льняных тканей, т.к. запаса прочности льна вполне достаточно.

Чем же отличаются и ценятся льняные ткани? В первую очередь очень хорошими гигиеническими (высокой воздухопроницаемостью, гигроскопичностью, теплопроводностью, влаговпитываемостью) и эксплуатационными (низкой загрязняемостью и хорошей отстирываемостью благодаря гладкой поверхности волокон) свойствами, а также прочностью. Есть и отрицательные свойства, например, низкая эластичность (слабая растяжимость). Однако, наряду с отрицательной позицией, это свойство определило их широкое использование в качестве прокладочных материалов. К основным недостаткам льняных тканей следует отнести слабую формоустойчивость и высокую сминаемость (из-за низкой упругости волокон), трудную отглаживаемость. Кроме того, льняные волокна из-за наличия в них примесей тяжело прокрашиваются. Хотя не яркие расцветки придают природный характер льняным тканям. По внешнему виду для льняных тканей характерна некоторая помятость, однако это подчеркивает премиальную особенность. 


\section{СИНТЕЗ МЕЖДИСЦИПЛИНАРНОГО НАУЧНОГО ЗНАНИЯ КАК ФАКТОР РАЗВИТИЯ СОВРЕМЕННОЙ НАУКИ}

Для нивелирования недостатков и повышения уровня положительных свойств льняные ткани выпускаются в смеске с хлопчатобумажными или химическими (искусственными или синтетическими) волокнами или пряжей. Льняные ткани с хлопчатобумажной пряжей более мягкие, лучше окрашиваются, имеют более привлекательный внешний вид. Добавление вискозы также способствует улучшению внешнего вида и драпируемости, а добавление лавсана повышает упругость и, соответственно, значительно снижает сминаемость, повышает износостойкость тканей. Нашли применение ткани из смески льна, вискозы и лавсана, имеющие букет положительных свойств. Однако любая добавка синтетических волокон при повышении эксплуатационных, ухудшает гигиенические свойства

Льняные ткани не электризуются. Кроме того, считается, что они ослабляют электромагнитное излучение (это важно для тех, кто много времени проводит за компьютером), предохраняют от химически агрессивной среды, имеют антисептические и антибактериальные свойства (что важно для людей с кожными заболеваниями) $[3,4,5]$.

Льняные ткани незаменимы для изделий летней одежды, особенно при ношении в очень жаркую погоду. Человек более комфортно себя чувствует в такой одежде благодаря тому, что льняные ткани за счет высокой воздухопроницаемости позволяют отводить от тела тепло и снижать температуру пододежного пространства на 3-4 градуса, т.е. выступают природным кондиционером $[4,5,6]$. Ткань не прилипает к потному телу и обладает признаком приятного ощущения.

Для летней одежды льняные ткани являются альтернативой хлопчатобумажным. Причем благодаря более высоким указанным выше потребительским свойствам предпочтения потребителей летней одежды меняются в сторону изделий из льняных тканей. Об этом говорят выставки моды. Согласно статистическим данным с 2016 года идет видимое увеличение потребления льняных тканей [7].

Из льняных тканей можно изготавливать одежду повседневной носки, деловую (офисную), а также форменную одежду. Наиболее популярными швейными изделиями из льняных тканей являются рубашки, платья, платьярубашки, сарафаны. Производителями предлагается многочисленные модели этих изделий.

Проведенное исследование в торговых центрах с помощью применения метода наблюдения о предпочтениях потребителей изделий из 
хлопчатобумажных и льняных тканей показало интересные результаты (табл. 1). Из карты наблюдений видно, что хотя покупок хлопчатобумажных изделий зафиксировано за период наблюдения больше, тем не менее, проявилась достаточно высокая заинтересованность к изделиям из льняных тканей.

\section{Таблица 1}

\section{Карта наблюдения}

\begin{tabular}{|c|c|c|}
\hline Поведение посетителей & \multicolumn{2}{|c|}{$\begin{array}{c}\text { Количество посетителей, } \\
\text { заинтересовавшихся изделиями из тканей: } \\
\text { хлопчатобумажных / льняных }\end{array}$} \\
\cline { 2 - 3 } & $\begin{array}{c}\text { Мужская рубашка } \\
\text { Платье-рубашка }\end{array}$ \\
\hline 1 & 2 & 3 \\
\hline Проход мимо товара (игнорирование) & $23 / 23$ & 18 / 18 \\
\hline Предпочтительно смотрят & $40 / 44$ & $35 / 36$ \\
\hline Померили, но не приобрели & & $10 / 14$ \\
\hline Приобрели без примерки & $35 / 30$ & $12 / 8$ \\
\hline Приобрели с примеркой & $0 / 1$ & \\
\hline
\end{tabular}

Интересные результаты дало также социологическое исследование о выявлении предпочтений в тканях при выборе изделий летней одежды. В опросе участвовало 95 респондентов, заинтересованных в приобретении предметов одежды.

На вопрос о выборе тканей из указанных четырех групп по составу сырья большинство (со значительным отрывом) респондентов высказалось за хлопчатобумажные ткани и на втором месте - льняные (рис. 1). Однако при изменении вопроса, т.е. при выборе из трех вариантов с указанием льняной ткани в смеси с хлопком, ответы оказались явно неожиданными - в пользу именно этой ткани (рис. 2). Дальнейшее уточнение сырьевого состава льняных тканей показало, что чисто льняные ткани по предпочтениям на втором месте после льняных тканей с хлопком, но все-таки $18 \%$ респондентов привержены к тканям, содержащим синтетическое волокно лавсан. 




Рис. 1. Предпочтения в выборе тканей для летней одежды 1 - хлопчатобумажные; 2 - льняные; 3 - вискозные; 4 - из синтетических волокон

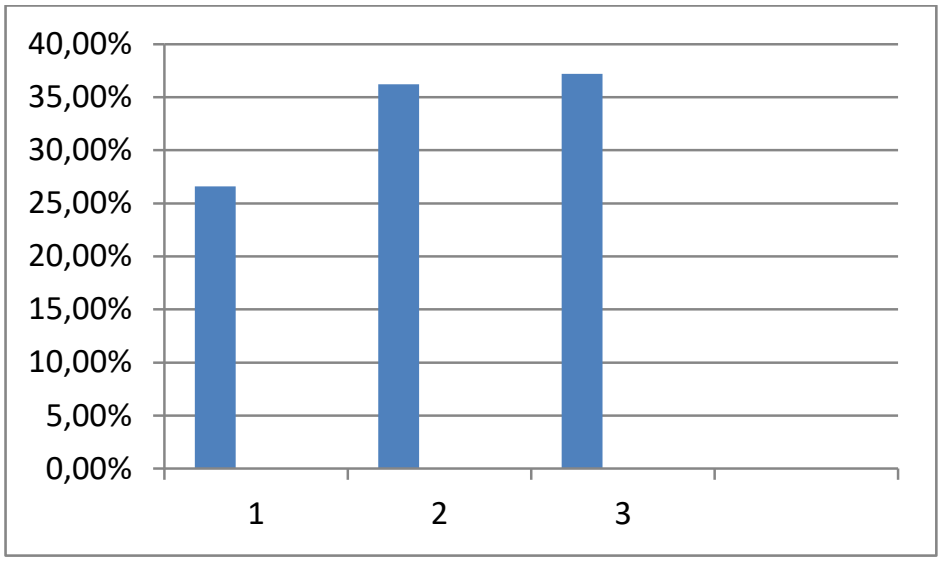

Рис. 2. Предпочтения в выборе тканей для летней одежды 1 - льняные; 2 - хлопчатобумажные; 3 - льняные в смеси с хлопком

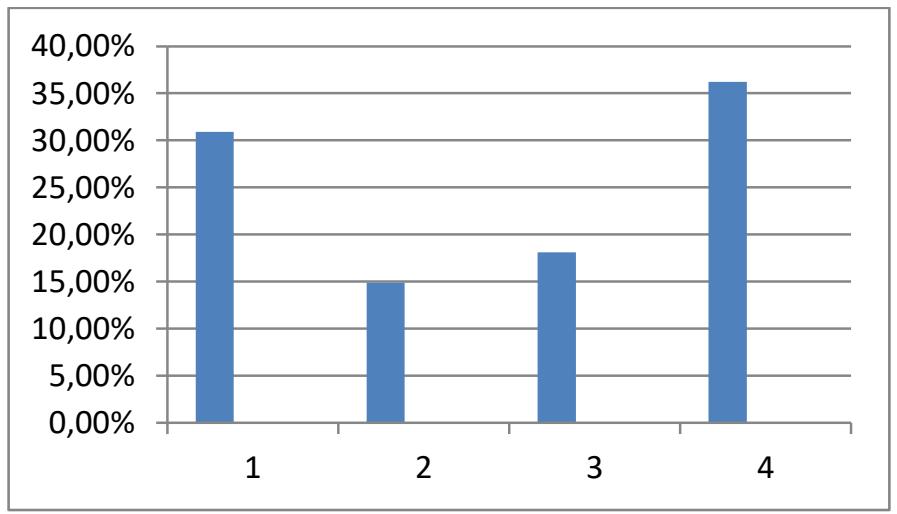

Рис. 3. Предпочтения в выборе тканей для летней одежды 1 - льняные; 2 - льняные в смеси с вискозой; 3- льняные в смеси с лавсаном; 4 - льняные в смеси с хлопком 


\section{СИНТЕЗ МЕЖДИСЦИПЛИНАРНОГО НАУЧНОГО ЗНАНИЯ КАК ФАКТОР РАЗВИТИЯ СОВРЕМЕННОЙ НАУКИ}

Таким образом, проведенный опрос подтвердил значительный интерес потребителей к изделиям из льняных тканей, в частности к предметам летней одежды. Предпочтения к льняным тканям, содержащим хлопчатобумажные волокна или пряжу, не явились предсказуемыми, но заслуживают внимание.

К сожалению, отечественная промышленность резко сократила производство льняных тканей и, хотя ассортимент швейных изделий имеет тенденцию к расширению, происходит это в основном за счет увеличения импорта.

\section{Список литературы}

1. Одежда: классификация и виды. [Электронный ресурс]. Режим доступа: mischas.ru>odezhda.html (дата обращения 8.10.2020 г.).

2. Главное, что нужно знать о льне: свойства, умягчение... [Электронный pecypc]. Режим доступа: tkano.ru〉blog/glavnoe-chto-nuzhno...lne... umyagchenie... (дата обращения 8.10.2020 г.).

3. Ткани для одежды - натуральный лен для одежды. [Электронный pecypc]. Режим доступа: izolna.ru〉...tkani/lnyanye-tkani-dlya-odezhdy/ (дата обращения 8.10.2020 г.).

4. Особенности льняных тканей. Натуральное чудо. [Электронный pecypc]. Режим доступа: tkani3000.ru>a131466-osobennosti-lnyanyh... (дата обращения 8.10.2020 г.).

5. Ассортимент тканей из льна. Искусство шить. [Электронный ресурс]. Режим доступа: t-stile.inforassortiment-tkanej-iz-lna/ (дата обращения 8.10.2020 г.).

6. Льняные ткани для одежды - преимущества. [Электронный ресурс]. Режим доступа: izolna.ru>catalog/tkani/lnyanye...dlya-odezhdy/ (дата обращения 8.10.2020 г.).

7. Рынок продукции текстильного производства. [Электронный ресурс]. Режим доступа: rosflaxhemp.ru>publikacii.html/id/2132 (дата обращения 8.10.2020 г.). 